\title{
Health Literacy: Prevalence among Elderly Care Givers and Its Impact on the Frequency of Elderly Hospitalization and Elderly Health Related Quality of Life
}

\author{
Tomader Taha Abdel Rahman \\ Geriatrics Medicine Department, Faculty of Medicine, Ain Shams University, Cairo, Egypt \\ Email: tomelhagyn@hotmail.com
}

Received 17 September 2014; revised 21 October 2014; accepted 11 November 2014

Academic Editor: Krishna Midde, University of California San Diego, USA

Copyright (C) 2014 by author and Scientific Research Publishing Inc.

This work is licensed under the Creative Commons Attribution International License (CC BY). http://creativecommons.org/licenses/by/4.0/

c) (i) Open Access

\begin{abstract}
Caring for the elderly is an extremely lonely and frustrating vigil. The care giver has the responsibility of caring for an elderly one to the myriad decisions on different topics such as diabetes care or cancer treatment. Care givers with low levels of health literacy have less health knowledge, worse management of chronic disease and lower use of preventive services. This study was conducted to determine the prevalence of health literacy among elderly care givers and its impact on the frequency of elderly hospitalization and elderly health related quality of life (QOL). The study was carried out on 200 elderly patients and their corresponding care givers. Rapid Estimate of Adult Literacy in Medicine (REALM) and Newest Vital Sign (NVS) were used to assess caregivers' health literacy. Assessment of the elderly health related QOL was done by the use of short form-12 health survey (SF-12). The results were as followed, in elderly patients; 92 were males and 108 were females. The mean elderly age was $69.4 \pm 8.8$. The mean age of caregivers was $42.1 \pm 12.9$ years. The prevalence of inadequate health literacy among elderly caregivers was $75.0 \%$. There were significant associations between care givers, health literacy and the frequency of elderly hospitalization $(p=0.001)$, duration of hospital stay $(p=0.009)$, and the elderly health related QOL $(p=0.001)$. The study concluded that inadequate health literacy is a problem among elderly care givers in Egypt. Healthcare professionals must be made aware of this problem, which is to provide simplified educational materials to elderly care givers to maximize elderly care.
\end{abstract}

\section{Keywords}

Care Givers, Health Literacy, Health Related Quality of Life, Frequency of Elderly Hospitalization 


\section{Introduction}

Health literacy has been defined as the ability to obtain, process, and understand basic information and services needed to make appropriate health decisions [1]. The elderly caregiver must be able to understand and use information in a meaningful way to be able to improve the elderly's health and nutrition [2]-[4].

In 2004, the Institutes of Medicine, the Agency for Healthcare Research and Quality, and the American Medical Association all issued reports about health literacy, noting that up to $50 \%$ of adults lack the literacy skills needed to function adequately in a health care environment.

Inadequate health literacy has been associated with increased incidence of hospitalizations [4]-[6]. However, other researchers didn't find this association [7] [8].

While health literacy has become a vibrant area of international research, Egypt has lagged behind and to date no data exist.

The aim of this study was to determine the prevalence of health literacy among elderly care givers and its impact on the frequency of elderly hospitalization and elderly health related quality of life (QOL).

\subsection{Study Design}

Cross sectional study.

\subsection{Study Settings}

The study was conducted at Geriatrics Medicine Department, Ain Shams University Hospitals, Egypt from June 2012 to June 2013. An informed oral consent was taken from each participant.

\section{Methods}

This study was conducted through two stages. Stage I, in which translation and retranslation of Rapid Estimate of Adult Literacy in Medicine (REALM) English version into Arabic version were done. Stage II, in which the prevalence of health literacy among elderly care givers was done, as well as the impact of care givers' health literacy on the frequency of elderly hospitalization and elderly health related QOL were done.

\subsection{Stage I}

Translation and retranslation of the 66 REALM medical terms into Arabic was done. The translation took into account both the dictionary definition and the commonality of usage in daily conversations. The REALM both the English and Arabic versions were tested with English speaking and Arabic speaking subjects. The Arabic version was identical to the English version. Test retest reliability data were collected from a sub sample of 20 participants.

\subsection{Stage II}

The study was carried out on 200 elderly patients and their corresponding care givers (200 care givers).

\subsection{Caregivers Assessments}

Two tools were used for care givers health literacy assessment; REALM [9] and the Newest Vital Sign (NVS) [10]. These two tools have been widely used in the research settings [11].

1) The REALM provides an estimate of the individual's reading and understanding ability. This instrument can be used in a clinical setting to identify subject with poor health literacy. It is a screening instrument of 66 routinely used lay medical terms. The words are arranged in three columns of 22 words each, on a standardized A4 sized paper, with the words enlarged and in black ink. The words are evenly spaced and presented in order of increasing difficulty.

There is no time limit for this test but most people with a normal level of literacy can complete the test in 2 - 3 minutes.

The care giver was asked to read the words aloud and interpret its meaning. The score was one point for every word red and interpreted correctly and zero if the word was mispronounced or not interpreted correctly. This 
gives a raw score from a maximum possible score of 66 . Score $>60$ indicates that the individual will be able to read and understand most patients, prescribed materials (adequate health literacy) [9].

2) The NVS is an accurate, objective, easy to administer, and well accepted measure that estimates health literacy. It requires only 3 minutes for administration, but achieves an estimate of functional health literacy by measuring numeric, mathematics, reading, and comprehension skills as well as abstract reasoning. It has high sensitivity in identifying those with inadequate health literacy [10]. The maximum possible score of NVS is 6 , score $\geq 4$ indicates adequate literacy.

In this study, Care giver was considered to have adequate health literacy if he/she has score of adequate literacy in both tests.

\subsection{Elderly Patients Assessment}

Comprehensive geriatric assessment was done for each elderly patient including demographics data, medical history taking, and assessment of health related QOL by the use of short form 12 health survey (SF-12) [12].

SF-12 [12] is a 12-item questionnaire that measures health related quality of life (QOL) across eight domains, which are both physically and emotionally based. For each domain, a score ranging from 0 (worst measured health) to 100 (best measured health) was calculated. SF-12 scales were further aggregated to produce physical component summary (PCS) and mental component summary (MCS) measurements of health status. The PCS and MCS were also scored using norm-based methods according to the participants' age and sex [13].

\subsection{Data Management and Statistical Analysis}

Data was collected and analytical statistics were done using the 15th version of statistical package for social sciences (SPSS, Chicago, IL, USA). In stage I, correlation between the results of testing REALM and retesting it was done using spearman correlation coefficient. In stage II, categorical data were compared between groups by $\chi^{2}$ test and continuous data were compared between groups using unpaired $t$ test for normally distributed variables. The p-value was always set at 0.05 .

\section{Results}

In stage I, test retest reliability data were collected from a sub sample of 20 participants. The participants were tested about $3.0 \pm 2.6$ days apart. the mean change in REALM Arabic version scores from the first to second evaluation was $0.9 \pm 1.2$ points, and correlation between the two evaluations was high (correlation coefficient $=$ $0.92, \mathrm{p}<0.001)$.

In stage II, the study was carried out on 200 elderly patients and 200 care givers. In elderly patients; 92 were males and 108 were females. The mean age was $69.4 \pm 8.8$. 88.0\% of them were illiterates. The mean duration of hospital stay was $7.9 \pm 6.3$ days. $54.5 \%$ of elderly were previously hospitalized more than 3 times. The most common causes of admission among elderly patients were chronic liver disease (34\%), stroke (27\%), uncontrolled hypertension (11.5\%), and chronic obstructive pulmonary disease (11.0\%) (Table 1). The mean age of caregivers was $42.1 \pm 12.9$ years, and $89.5 \%$ were females (Table 2). The prevalence of inadequate health literacy among elderly care givers was $75.0 \%$ (Table 3 ). There were significant associations between health literacy and care givers, age $(\mathrm{p}<0.001)$, care givers' sex $(\mathrm{p}<0.001)$, care givers, education level $(\mathrm{p}<0.001)$, frequency of hospital admission of the elderly patients $(\mathrm{p}=0.001)$, duration of hospital stay $(\mathrm{p}=0.009)$, and the elderly health related QOL both physical component summary (PCS) $(\mathrm{p}=0.001)$ and mental component summary (MCS) $(\mathrm{p}=0.001)$ (Table 4).

\section{Discussion}

Everyday in the Geriatrics Medicine Department, Ain Shams University Hospital, care givers are given written or verbal information about their patients' medical condition(s) and/or prevention of disease. To have appropriate decision regarding a patient's health care needs, a physician must know the average health literacy level of care givers [14] [15].

There was no available data describing the problem of inadequate health literacy among elderly care givers in Egypt. The present study is the most recent of its kind to be carried out in Egypt, and it widens the evidence base for policy and practice initiatives. 
Table 1. Elderly patient's characteristics.

\begin{tabular}{|c|c|c|}
\hline \multicolumn{3}{|l|}{ Studied variables } \\
\hline Age (years) (mean \pm SD) & \multicolumn{2}{|c|}{$69.4 \pm 8.8$} \\
\hline Female sex (number) (\%) & 108 & $54.0 \%$ \\
\hline \multicolumn{3}{|l|}{ Education (number) (\%) } \\
\hline Illiterate & 176 & $88.0 \%$ \\
\hline Primary & 5 & $2.5 \%$ \\
\hline Preparatory & 7 & $3.5 \%$ \\
\hline Secondary & 9 & $4.5 \%$ \\
\hline High education & 3 & $1.5 \%$ \\
\hline \multicolumn{3}{|l|}{ Marital status (number) (\%) } \\
\hline Single & 108 & $54.0 \%$ \\
\hline Married & 92 & $46.0 \%$ \\
\hline Duration of hospital stay (days) & & $7.9 \pm 6.3$ \\
\hline \multicolumn{3}{|l|}{ Frequency of hospital admission (number) (\%) } \\
\hline$>3$ times & 109 & $54.5 \%$ \\
\hline$<3$ times & 91 & $45.5 \%$ \\
\hline \multicolumn{3}{|l|}{ Cause of admission (number) (\%) } \\
\hline Chronic liver disease & 68 & $34.0 \%$ \\
\hline Stroke & 54 & $27.0 \%$ \\
\hline Uncontrolled hypertension & 23 & $11.5 \%$ \\
\hline Chronic obstructive pulmonary disease & 22 & $11.0 \%$ \\
\hline Chronic renal failure & 21 & $10.5 \%$ \\
\hline Heart failure & 6 & $3.0 \%$ \\
\hline Uncontrolled diabetes & 3 & $1.5 \%$ \\
\hline Cancer & 3 & $1.5 \%$ \\
\hline Total health related QOL & & $30.7 \pm 27.4$ \\
\hline Physical component summary of health related QOL & & $26.7 \pm 29.5$ \\
\hline Mental component summary of health related QOL & & $34.7 \pm 28.9$ \\
\hline
\end{tabular}

QOL: quality of life.

\section{Table 2. Care givers' characteristics.}

\begin{tabular}{lcc}
\hline & Number & Percent \\
\hline Care giver's age & 36 & $18.0 \%$ \\
$<30$ years & 87 & $43.5 \%$ \\
30 - 50 years & 77 & $38.5 \%$ \\
$>50$ years & & $42.1 \pm 12.9$ \\
Care giver's age (years) (mean \pm SD) & 179 & $89.5 \%$ \\
Females & & $37.0 \%$ \\
Education & 74 & $1.5 \%$ \\
Can read and write & 3 & $3.0 \%$ \\
Primary & 6 & $37.5 \%$ \\
Preparatory & 75 & $21.0 \%$ \\
Secondary & 42 & $36.6 \pm 29.6$ \\
High education & & $2.7 \pm 2.5$ \\
REALM (mean \pm SD) & & \\
NVS (mean \pm SD) & & \\
\hline
\end{tabular}

REALM: Rapid Estimate of Adult Literacy in Medicine; NVS: Newest Vital Sign. 
Table 3. Prevalence of health literacy among elderly care givers.

\begin{tabular}{cccccc}
\hline & \multicolumn{2}{c}{ Inadequate health literacy } & \multicolumn{2}{c}{ Adequate health literacy } & p value \\
\hline & Number & Percent (\%) & Number & Percent (\%) & \\
Males & 9 & $42.9 \%$ & 12 & $57.1 \%$ & $<0.001$ \\
Females & 141 & $78.8 \%$ & 38 & $21.2 \%$ & $25.0 \%$ \\
\hline Total & 150 & $75.0 \%$ & 50 & & \\
\hline
\end{tabular}

Table 4. The association between care givers health literacy and the frequency of elderly hospital admission and health related QOL.

\begin{tabular}{|c|c|c|c|c|c|c|}
\hline & & \multicolumn{2}{|c|}{ Inadequate health literacy } & \multicolumn{2}{|c|}{ Adequate health literacy } & $\mathrm{p}$ value \\
\hline \multirow{3}{*}{ Care givers age (years) } & $<30$ & 36 & $100 \%$ & 0 & $0.0 \%$ & \multirow{3}{*}{$<0.001$} \\
\hline & $30-50$ & 45 & $51.7 \%$ & 42 & $48.3 \%$ & \\
\hline & $>50$ & 69 & $89.6 \%$ & 8 & $10.4 \%$ & \\
\hline \multirow{2}{*}{ Care givers sex } & Male & 9 & $42.9 \%$ & 12 & $57.1 \%$ & \multirow{2}{*}{$<0.001$} \\
\hline & Female & 141 & $78.8 \%$ & 38 & $21.2 \%$ & \\
\hline \multicolumn{2}{|l|}{ Care givers education (years) (mean \pm SD) } & \multicolumn{2}{|c|}{$7.8 \pm 3.1$} & \multicolumn{2}{|c|}{$11.6 \pm 4.2$} & $<0.001$ \\
\hline \multirow{3}{*}{ Duration of hospital stay (days) } & $<5$ days & 53 & $63.9 \%$ & 30 & $36.1 \%$ & \multirow{3}{*}{0.009} \\
\hline & 5 - 10 days & 37 & $82.2 \%$ & 8 & $17.8 \%$ & \\
\hline & $>10$ days & 60 & $83.3 \%$ & 12 & $16.7 \%$ & \\
\hline \multirow{2}{*}{ Frequency of hospitalization } & $>3$ times & 92 & $84.4 \%$ & 17 & $15.6 \%$ & \multirow{2}{*}{0.001} \\
\hline & $<3$ times & 58 & $63.7 \%$ & 33 & $36.3 \%$ & \\
\hline Physical component summary of health related QOL & Abnormal & 109 & $69.4 \%$ & 48 & $30.6 \%$ & 0.001 \\
\hline Mental component summary of health related QOL & Abnormal & 91 & $71.1 \%$ & 37 & $28.9 \%$ & 0.001 \\
\hline
\end{tabular}

The present study provides a reliable estimate of health literacy, as multiple tools for assessment of health literacy were used. This study revealed that only $25.0 \%$ of the care givers have adequate health literacy while $75.0 \%$ have inadequate health literacy.

In United States, studies reported that 34\% to 51\% of American adults had low levels of health literacy [16].

Montalto and Spiegler [17] conducted a study at a rural community health center where 183 adult patients were invited to participate. They used the Short Test of Functional Health Literacy in Adults. Approximately $15 \%$ demonstrated inadequate health literacy.

Lindquist and colleagues used The Test for Functional Health Literacy and they demonstrated that $36 \%$ of caregivers hired privately or through an agency were found to have limited health literacy [18].

This study reported very high level of inadequate health literacy among care givers (75.0\%); this could be due to the differences between Egypt and the other countries in culture and socioeconomic status. As well as, other studies used one tool in assessment of health literacy while this study used two reliable estimates of health literacy.

In agreement with previous studies [6] [19]-[22], this study reported a significant association between health literacy and age $(\mathrm{p}<0.001)$.

In the current study inadequate health literacy was significantly detected more among female care givers than male care givers ( $\mathrm{p}<0.001)$. This comes in adherence to Goggins et al. [23] who reported that female gender is independently associated with inadequate health literacy due to low educational status.

In this study, fewer years of formal education was associated with inadequate adult health literacy, a finding that is consistent with previous researches [20] [24]-[26]. Previous studies reported that when a person has advanced general literacy, their ability to obtain, understand and apply health care information can be adequate [19] [27]. 
Few studies have examined the relationship between health literacy and adverse health outcomes. It was detected that inadequate health literacy was associated with $29 \%$ to $52 \%$ higher hospitalization rates, even after adjustment for baseline socioeconomic status, health status, and health behaviors [21] [28].

In this study there were significant associations between care givers' health literacy and frequency of hospital admission ( $p=0.001)$, duration of elderly hospital stay $(p=0.009)$, and elderly health related QOL (both PCS and MCS) $(p=0.001)$. It has been suggested that inadequate health literacy may have a direct, negative effect on health [29]. It is well established that low health literacy can significantly limit the individual's ability to prevent and manage disease [6] [30]-[32]. Individuals with limited health literacy are less likely to participate in preventive measures, such as mammograms and immunization schemes [32] [33]. It has also been demonstrated that limited health literacy is associated with an increased frequency of poor management to chronic conditions such as diabetes and hypertension with high frequency of hospital admission [21] [34]. Similarly, these individuals are more likely to give medication incorrectly and leading to high frequency of elderly hospital visits and even hospitalization [21] [32] [34].

One of the most important outcomes in health care interventions is health related QOL. Evidence about the relationship between health literacy and health related QOL is limited [35]. This study showed that health literacy was significantly affecting both physical as well as mental component summary of health related QOL $(\mathrm{p}=$ 0.001). These results come in adherence to Alireza and Nader study [36].

With a trend worldwide towards personalized medicine, this theme should be extended to include tailor made personalized health care information [37]. If physicians determined care givers' level of health literacy, they may be able to tailor information and materials provided to the care givers to maximize elderly care and increase the likelihood of favorable clinical outcomes.

An investment in care givers health literacy will ultimately improve patient outcomes and safety. Being health literate enables care givers to make proper decisions, and to influence events [38]. The level of health literacy may be increased by education programs [39].

\section{Conclusion}

The study concluded that inadequate health literacy is a problem among elderly care givers in Egypt. Healthcare professionals must be made aware of this problem, which is to provide simplified educational materials to elderly care givers to maximize elderly care. As well, heath education programs may be provided for elderly care givers.

\section{References}

[1] Berkman, N., DeWalt, D., Pignone, M., et al. (2004) Literacy and Health Outcomes. Summary, Evidence Report/Technology Assessment No. 87. Agency for Healthcare Research and Quality, Rockville.

[2] Wallace, L., North American Primary Care Research Group (2006) Patients' Health Literacy Skills: The Missing Demographic Variable in Primary Care Research. Annals of Family Medicine, 4, 85-86. http://dx.doi.org/10.1370/afm.501

[3] Davis, T.C., Wolf, M.S., Bass III, P.F., et al. (2006) Literacy and Misunderstanding Prescription Drug Labels. Annals of Internal Medicine, 145, 887-894. http://dx.doi.org/10.7326/0003-4819-145-12-200612190-00144

[4] Sheridan, S.L., Harris, R.P. and Woolf, S.H., for the Shared-Decision Making Work Ground of the United States Preventative Task Force (2003) Shared Decision Making about Screening and Chemoprevention, a Suggested Approach from the U.S. Preventative Services Task Force. Agency for Healthcare Research and Quality, Rockville.

[5] US Department of Health and Human Services. Health Communication. In: Healthy People (2010) Understanding and Improving Health and Objectives for Improving Health. 2nd Edition, US Government Printing Office, Washington, DC.

[6] Schillinger, D., Grumbach, K., Piette, J., et al. (2002) Association of Health Literacy and Diabetes Outcomes. JAMA, 288, 475-482. http://dx.doi.org/10.1001/jama.288.4.475

[7] Osborn, C.Y., Weiss, B.D., Davis, T.C., et al. (2007) Measuring Adult Literacy in Health Care: Performance of the Newest Vital Sign. American Journal of Health Behavior, 31, S36-S46. http://dx.doi.org/10.5993/AJHB.31.s1.6

[8] Kim, S., Love, F., Quistber, D.A., et al. (2004) Association of Health Literacy with Self-Management Behavior in Patients with Diabetes. Diabetes Care, 27, 2980-2982. http://dx.doi.org/10.2337/diacare.27.12.2980

[9] Davis, T.C., Long, S.W., Jackson, R.H., et al. (1993) Rapid Estimate of Adult Literacy in Medicine: A Shortened 
Screening Instrument. Annals of Family Medicine, 25, 391-395.

[10] Weiss, B.D., Mays, M.Z., Martz, W., et al. (2005) Quick Assessment of Literacy in Primary Care: The Newest Vital Sign. Annals of Family Medicine, 3, 514-522. http://dx.doi.org/10.1370/afm.405

[11] Von Wagner, C., Steptoe, A., Wolf, M.S. and Wardle, J. (2009) Health Literacy and Health Actions: A Review and a Framework from Health Psychology. Health Education \& Behavior, 36, 860-877. http://dx.doi.org/10.1177/1090198108322819

[12] Ware, J.E., Kosinski, M. and Keller, S.D. (1996) A 12-Item Short-Form Health Survey: Construction of Scales and Preliminary Tests of Reliability and Validity. Medical Care, 34, 220-233. http://dx.doi.org/10.1097/00005650-199603000-00003

[13] Ware, J.E., Kosinski, M. and Keller, S.K. (1994) Short Form (SF) Physical and Mental Health Summary Scales: A User's Manual. The Health Institute, New England Medical Center, Boston.

[14] Bass III, P.F., Wilson, J.F., Griffith, C.H. and Barnett, D.R. (2002) Residents’ Ability to Identify Patients with Poor Literacy Skills. Academic Medicine, 77, 1039-1041. http://dx.doi.org/10.1097/00001888-200210000-00021

[15] Rogers, E.S., Wallace, L.S. and Weiss, B.D. (2006) Misperceptions of Medical Understanding in Low-Literacy Patients: Implications for Cancer Prevention. Cancer Control, 13, 225-229.

[16] Kutner, M., Greenberg, E., Jin, Y., et al. (2006) The Health Literacy of America’s Adults. Results from the 2003 National Assessment of Adult Literacy. National Center for Education Statistics, US Department of Education, Washington DC.

[17] Montalto, N. and Spiegler, G. (2001) Functional Health Literacy in Adults in a Rural Community Health Center. West Virginia Medical Journal, 97, 111-114.

[18] Lindquist, L.A., Jain, N., Tam, K., Martin, G.J. and Baker, D.W. (2011) Inadequate Health Literacy among Paid Caregivers of Seniors. Journal of General Internal Medicine, 26, 474-479. http://dx.doi.org/10.1007/s11606-010-1596-2

[19] Benson, J.G. and Forman, W.B. (2002) Comprehension of Written Health Care Information in an Affluent Geriatric Retirement Community: Use of the Test of Functional Health Literacy. Gerontology, 48, 93-97. http://dx.doi.org/10.1159/000048933

[20] Downey, L.V. and Zun, L.S. (2008) Assessing Adult Health Literacy in Urban Healthcare Settings. Journal of the National Medical Association, 100, 1304-1308.

[21] Baker, D.W., Gazmararian, J.A., Williams, M.V., Scott, T., Parker, R.M., Green, D., Ren, J.L. and Peel, J. (2002) Functional Health Literacy and the Risk of Hospitalization among Medicare Managed Care Enrollees. American Journal of Public Health, 92, 1278-1283. http://dx.doi.org/10.2105/AJPH.92.8.1278

[22] Wolf, M.S., Gazmararian, J.A. and Baker, D.W. (2005) Health Literacy and Functional Health Status among Older Adults. JAMA Internal Medicine, 165, 1946-1952. http://dx.doi.org/10.1001/archinte.165.17.1946

[23] Goggins, K.M., Wallston, K.A., Nwosu, S., Schildcrout, J.S., Castel, L., Kripalani, S., et al. (2014) Health Literacy, Numeracy, and Other Characteristics Associated with Hospitalized Patients' Preferences for Involvement in Decision Making. Journal of Health Communication, 19, 29-43.

[24] Levinthal, B.R., Morrow, D.G., Tu, W.Z., Wu, J.W. and Murray, M.D. (2008) Cognition and Health Literacy in Patients with Hypertension. Journal of General Internal Medicine, 23, 1172-1176. http://dx.doi.org/10.1007/s11606-008-0612-2

[25] Morrow, D., Clark, D., Tu, W., Wu, J.W., Weiner, M., Steinley, D. and Murray, M.D. (2006) Correlates of Health Literacy in Patients with Chronic Health Failure. Gerontologist, 46, 669-676. http://dx.doi.org/10.1093/geront/46.5.669

[26] Li, L., Li, Y., Nie, X., Huang, X., Shi, M., Li, F. and Wei, W. (2014) An Analysis of Health Literacy about Diabetes Prevention and Control and Its Influencing Factors among the Residents in Six Provinces in China. Zhonghua Yu Fang Yi Xue Za Zhi, 48, 561-565.

[27] Cho, Y.I., Lee, S.Y., Arozullah, A.M. and Crittenden, K.S. (2008) Effects of Health Literacy on Health Status and Health Service Utilization amongst the Elderly. Social Science \& Medicine, 66, 1809-1816. http://dx.doi.org/10.1016/j.socscimed.2008.01.003

[28] Dewalt, D.A. and Pignone, M.P. (2005) The Role of Literacy in Health and Health Care. American Family Physician, 72, 387-388.

[29] Williams, M.V., Baker, D.W., Honig, E.G., Lee, T.M. and Nowlan, A. (1998) Inadequate Literacy Is a Barrier to Asthma Knowledge and Self-Care. Chest, 114, 1008-1015. http://dx.doi.org/10.1378/chest.114.4.1008

[30] Schillinger, D., Grumbach, K., Piette, J., Wang, F., Osmond, D., Daher, C., et al. (2002) Association of Health Literacy with Diabetes Outcomes. JAMA, 288, 475-482. http://dx.doi.org/10.1001/jama.288.4.475

[31] Miller Jr., D.P., Brownlee, C.D., McCoy, T.P. and Pignone, M.P. (2007) The Effect of Health Literacy on Knowledge and Receipt of Colorectal Cancer Screening: A Survey Study. BMC Family Practice, 8, 16. 
http://dx.doi.org/10.1186/1471-2296-8-16

[32] Marshall, S., Sahm, L. and McCarthy, S. (2012) Health Literacy in Ireland: Reading between the Lines. Perspectives in Public Health, 132, 31-38. http://dx.doi.org/10.1177/1757913911431034

[33] Scott, T.L., Gazmararian, J.A., Williams, M.V. and Baker, D.W. (2002) Health Literacy and Preventive Health Care Use among Medicare Enrollees in a Managed Care Organization. Medical Care, 40, 395-404. http://dx.doi.org/10.1097/00005650-200205000-00005

[34] Nie, X.Q., Li, Y.H., Li, L. and Huang, X.G. (2014) A Study on Health Information Literacy among Urban and Suburban Residents in Six Provinces in China. Zhonghua Yu Fang Yi Xue Za Zhi, 48, 566-570.

[35] Hahn, E.A., Cella, D., Dobrez, D.G., Weiss, B.D., Du, H.Y., Lai, J.S., et al. (2007) The Impact of Literacy on Health Related Quality of Life Measurement and Outcomes in Cancer Outpatients. Quality of Life Research, 16, 495-507. http://dx.doi.org/10.1007/s11136-006-9128-6

[36] Jahanlou, A.S. and Alishan Karami, N. (2011) The Effect of Literacy Level on Health Related-Quality of Life, SelfEfficacy and Self-Management Behaviors in Diabetic Patients. Acta Medica Iranica, 49, 153-158.

[37] Marshall, S., Sahm, L. and McCarthy, S. (2012) Health Literacy in Ireland: Reading between the Lines. Perspectives in Public Health, 132, 31-38.

[38] Institute of Medicine (2004) Health Literacy: A Prescription to End Confusion. National Academies Press, Washington DC.

[39] WHO (2009) Background Note: Regional Preparatory Meeting on Promoting Health Literacy [Internet]. UN ECOSOC, Geneva.

\author{
Abbreviations \\ QOL: Quality of Life \\ REALM: Rapid Estimate of Adult Literacy in Medicine \\ NVS: Newest Vital Sign \\ SF-12: Short Form-12. \\ PCS: Physical Component Summary \\ MCS: Mental Component Summary
}


Scientific Research Publishing (SCIRP) is one of the largest Open Access journal publishers. It is currently publishing more than 200 open access, online, peer-reviewed journals covering a wide range of academic disciplines. SCIRP serves the worldwide academic communities and contributes to the progress and application of science with its publication.

Other selected journals from SCIRP are listed as below. Submit your manuscript to us via either submit@scirp.org or Online Submission Portal.
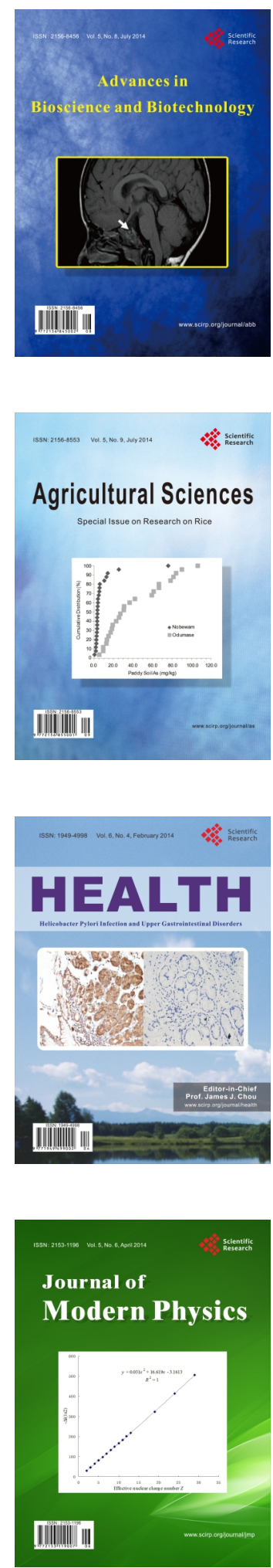
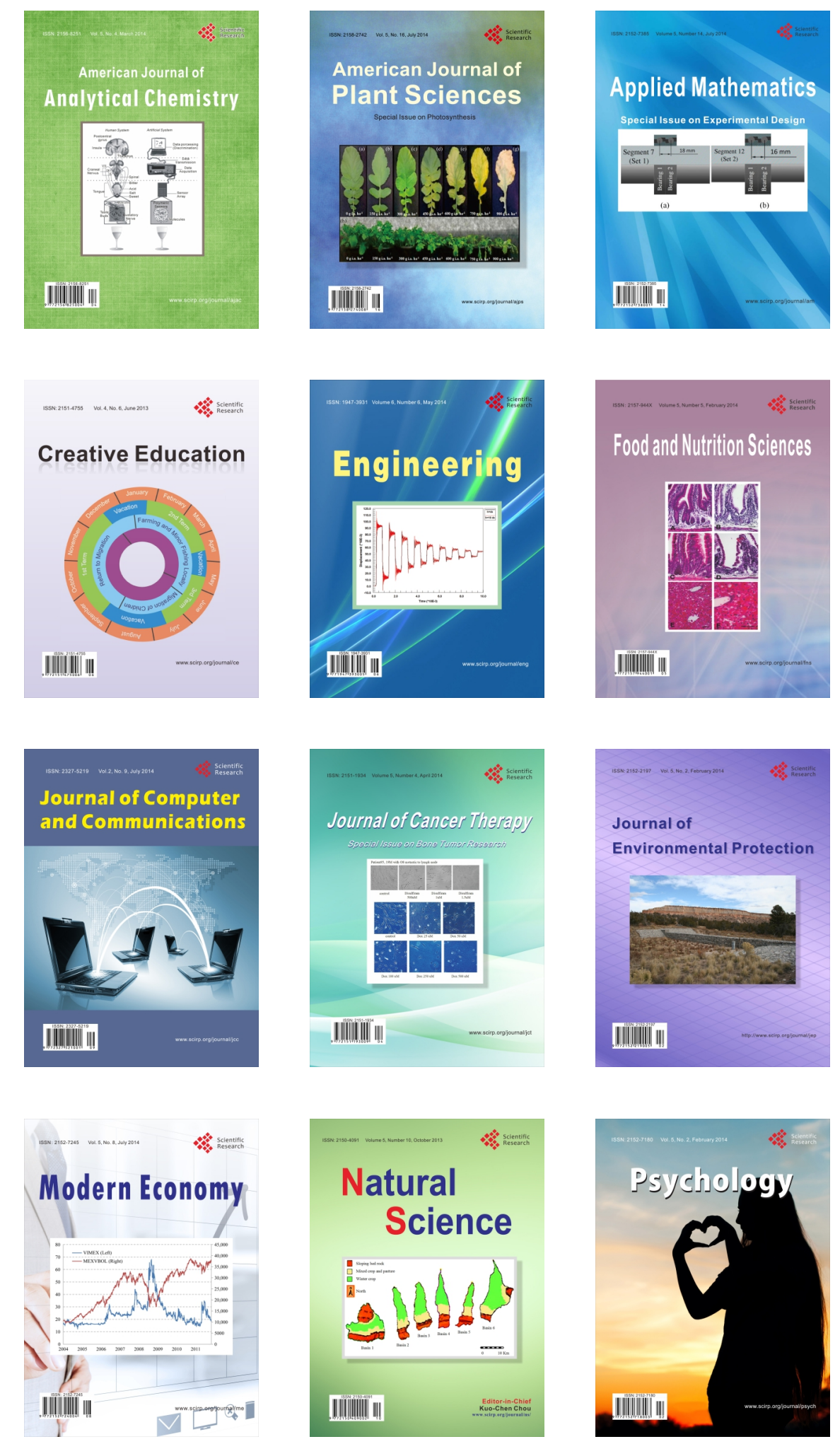